\title{
Prevalence and Antimicrobial Sensitivity Pattern of Urinary Tract Infection in Febrile Children Aged 1 Month to 5 Years
}

\author{
Saravanan.S \\ [Assistant professor, Department of Pediatrics, Meenakshi medical college \& research institute, MAHER \\ University, Tamilnadu, India]
}

\section{Introduction}

Urinary tract infection (UTI) is a common infection in infants and children. During infancy, boys are more commonly affected than girls and thereafter, female preponderance is found. Presentation varies among different age groups. Clinical features in neonates and young infants are non-specific, manifest as septicemia where a high index of suspicion is needed. Older children typically present as simple or complicated UTI. Rapid diagnosis, institution of early treatment and further evaluation by imaging modalities are of utmost importance. This was a prospective study in febrile children from 1month to 5years at Meenakshi medical college hospital and research institute from Jan 2011 - Dec 2012.

\section{Material And Methods}

Children who presented with fever were included and those with known congenital genitourinary anomalies and those who received antibiotics 48 hours prior were excluded. Routine blood counts, urinary analysis was done. The urine specimens were centrifuged in a standard manner and in those showing (pus cells $>5 \mathrm{HPF}$ in centrifuged urine), a clean catch mid stream urine sample was sent for culture which was incubated on Blood and MacConkey agar plates with a $0.01 \mathrm{ml}$ calibrated loop. All plates were incubated at $35-37^{\circ} \mathrm{C}$ for $24 \mathrm{hrs}$ under aerobic condition to obtain accurate colony count. On culture of mid stream sample of urine, a colony count of more than $10^{5} / \mathrm{ml}$ organisms of a single species was considered significant. Sample showing insignificant growth, mixed growth of two or more pathogens or growth of non-pathogens were not considered as culture positive. Antibiotic sensitivity was put up by the Kirby Bauer method following the clinical laboratory standard institute (CLSI) ${ }^{19}$ guidelines.

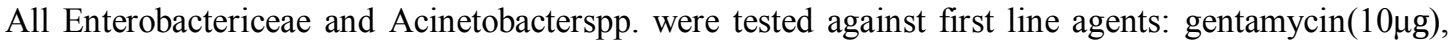
amikacin $(30 \mu \mathrm{g})$, nitrofurantoin $(300 \mu \mathrm{g})$, trimethoprim sulphamethoxazole(1.25-23.75 $\mu \mathrm{g})$, norfloxacin $(10 \mu \mathrm{g})$, ciprofloxacin $(5 \mu \mathrm{g})$, amoxyclav $(20 / 10 \mu \mathrm{g})$ and tobramycin $(10 \mu \mathrm{g})$, Pseudomonas aeruginosa against amikacin $(30 \mu \mathrm{g})$, gentamicin $(10 \mu \mathrm{g})$, ceftazidime $(30 \mu \mathrm{g})$ and ciprofloxacin $(5 \mu \mathrm{g})$. Staph spp was tested against vancomycin $(30 \mu \mathrm{g})$.Second line antibiotics to all $1^{\text {st }}$ line antimicrobials or specifically requested for by the attending physicians. These included: Imipenem $(10 \mu \mathrm{g})$ and piperacillin-tazobactam $(100 / 10 \mu \mathrm{g})$ for all Enterobacteriaceae, Acinetobacter spp. and Pseudomonas isolates.

\section{Results And Analysis}

A total of 630 Children (1month to 5yrs) were evaluated in the study. Of 630 cases $305(48.4 \%)$ were males, 325(51.5\%) were females, 193 cases were < lyear (30.6\%) [90(14.2\%) males, 103(16.34\%) females], 195(30.9\%) [95(15\%) males, 100(15.87\%) females] cases were between $1-2$ years and 242(38.4\%) [120(19\%) males, $122(19.36 \%)$ females] cases were more than 2 years. Minimum age in the study group was 1 month and maximum age in the study group was 60 months.

\subsection{AGE AND SEX DISTRIBUTION OF SUBJECTS WITH URINE SHOWING > 5PUS CELLS/ HPF} TABLE -1

\begin{tabular}{|l|l|l|c|}
\hline \multirow{2}{*}{ Age } & \multicolumn{2}{|c|}{ Sex } & \multirow{2}{*}{ Total } \\
\cline { 2 - 3 } & Male & Female & $40(31.2 \%)$ \\
\hline$<1$ year & $20(15.6 \%)$ & $20(15.6 \%)$ & $35(27.3 \%)$ \\
\hline $1-2$ years & $15(11.7 \%)$ & $20(15.6 \%)$ & $53(41.4 \%)$ \\
\hline $2-5$ years & $21(16.4 \%)$ & $32(25 \%)$ & $128(100)$ \\
\hline Total & 56 & 72 & \\
\hline
\end{tabular}

Significant pyuria was seen in 128 children, of whom children between 2-5 yrs of age were predominant group and further analysis showed patients with 8-10 pus cells /HPF being the highest among the group (table-2). 


\subsection{DISTRIBUTION OF PUS CELLS IN URINE}

TABLE - 2

\begin{tabular}{|l|l|l|l|}
\hline No of Pus cells in Urine & \multicolumn{1}{|c|}{ Male } & Female & \multicolumn{1}{|c|}{ Total } \\
\hline $6-8$ & & & \\
\hline $8-10$ & $22(17.1 \%)$ & $26(20.3 \%)$ & $48(37 \%)$ \\
\hline Numerous & $25(19.5 \%)$ & $30(23.4 \%)$ & $55(43 \%)$ \\
\hline Total & $11(8.5 \%)$ & $14(10.9 \%)$ & $25(20 \%)$ \\
\hline
\end{tabular}

\subsection{DISTRIBUTION OF UTI IN ACCORDANCE WITH AGE}

TABLE- 3

\begin{tabular}{|l|l|l|}
\hline age & Total no of pts & Culture positivity \\
\hline$<1$ & 193 & $22(11.3 \%)$ \\
\hline $1-2$ & 195 & $18(9.2 \%)$ \\
\hline $2-5$ & 242 & $29(11.9 \%)$ \\
\hline & 630 & $69(10.9 \%)$ \\
\hline
\end{tabular}

\subsection{CORRELATION BETWEEN PYURIA AND UTI}

TABLE-4

\begin{tabular}{|l|l|l|l|l|l|l|}
\hline Age & Males with pyuria & $\begin{array}{l}\text { Females with } \\
\text { pyuria }\end{array}$ & $\begin{array}{l}\text { Total pyuric } \\
\text { children }\end{array}$ & Male UTI & $\begin{array}{l}\text { Female } \\
\text { UTI }\end{array}$ & Overall UTI \\
\hline$<1$ year & $20(15.6 \%)$ & $20(15.6 \%)$ & $40(31.2 \%)$ & $13(65 \%)$ & $9(45 \%)$ & $22(55 \%)$ \\
\hline $1-2$ years & $15(11.7 \%)$ & $20(15.6 \%)$ & $35(27.3 \%)$ & $7(46 \%)$ & $11(55 \%)$ & $18(51.4 \%)$ \\
\hline $2-5$ years & $21(16.4 \%)$ & $32(25 \%)$ & $53(41.4 \%)$ & $10(47 \%)$ & $19(59 \%)$ & $29(54.7 \%)$ \\
\hline Total & $56(43.7 \%)$ & $72(56.2 \%)$ & $128(100)$ & & & $69(53.9 \%)$ \\
\hline
\end{tabular}

\subsection{MICROBIOLOGICAL PROFILE AND PERCENTAGE DISTRIBUTION OF ISOLATES}

TABLE-5

\begin{tabular}{|l|l|l|l|}
\hline \multirow{2}{*}{ Culture report } & \multicolumn{2}{|c|}{ Sex } & \multirow{2}{*}{ Total } \\
\cline { 2 - 3 } & Male & Female & \\
\hline E coli & $17(24.6 \%)$ & $23(33.3 \%)$ & $40(57.97 \%)$ \\
\hline Klebsiella & $3(4.3 \%)$ & $5(7.2)$ & $8(11.59 \%)$ \\
\hline Pseudomonas & $3(4.3 \%)$ & $4(5.7 \%)$ & $7(10.14 \%)$ \\
\hline Proteus & $2(2.8 \%)$ & $2(2.8 \%)$ & $4(5.79 \%)$ \\
\hline CONS & $2(2.8 \%)$ & $2(2.8 \%)$ & $4(5.79 \%)$ \\
\hline Staph aureus & $1(1.4 \%)$ & $2(2.8 \%)$ & $3(4.34 \%)$ \\
\hline Acinetobacterspp & - & $1(1.4 \%)$ & $1(1.4 \%)$ \\
\hline Citrobacter & $1(1.4 \%)$ & - & $1(1.4 \%)$ \\
\hline Candida Spp. & - & $1(1.4 \%)$ & $1(1.4 \%)$ \\
\hline & $29(42.02 \%)$ & $40(57.9 \%)$ & $69(100 \%)$ \\
\hline
\end{tabular}

With reference to tables 3-5 UTI was overall more common in females and in age 2-5 years, when comparing UTI in children with pyuria, age 1month to one year was more common being 55\% than age group $2-5$ years $(54.7 \%)$.Culture positivity in patients with significant pyuria was high $53.9 \%$. Most common organism isolated was E.coli 40(57.97\%) followed by Klebsiella 8(11.59\%), Pseudomonas7 (10.14\%), Proteus 4(5.79\%), CONS 4(5.79\%), Staph aureus 3(4.34\%), Acinetobacterspp 1 (1.4\%), Citrobacter 1 (1.4\%), Candida spp 1 $(1.4 \%)$.

\subsection{ANTIBIOTIC SUSCEPTIBILITY PATTERNS OF BACTERIA IN CHILDREN WITH UTI IN} PERCENTAGE

TABLE-6

\begin{tabular}{|l|l|l|l|l|l|l|l|l|l|l|l|l|}
\hline Isolate & IMP & CIP & CEF & AMK & NIT & AMC & GEM & TOB & VAN & COT & NOR & PTT \\
\hline E.coli & 100 & 100 & - & 97 & 94.5 & 87 & 73.3 & 93 & - & 28 & 61.1 & \\
\hline Klebsiella & 100 & 100 & - & 95 & 92 & 81 & 44 & 97 & - & 21 & 21 & 100 \\
\hline P. aeruginosa & 100 & 89 & 100 & 89 & 76 & & 28 & 100 & - & 0 & 32 & 100 \\
\hline P. mirabilis & 100 & 86 & - & 82 & 51 & 88 & 34 & 98 & - & 16 & 83 & 100 \\
\hline CONS & - & 97 & - & 79 & 36 & 87 & 53 & 62 & 100 & 0 & 52 & - \\
\hline S. aureus & 40 & 91 & - & 88 & 27 & 78 & 70 & 67 & 100 & 0 & 47 & - \\
\hline Acinetobacterspp & 100 & 100 & - & 100 & 0 & 0 & 0 & 100 & - & 0 & 100 & 100 \\
\hline Citrobacter & 100 & 100 & - & 100 & 100 & 100 & 100 & 100 & - & 100 & 100 & 100 \\
\hline
\end{tabular}


Imipenem (IMP), ceftazidime (CEF), ciprofloxacin (CIP), amikacin (AMK), nitrofurantoin (NIT), coamoxiclav (AMC), gentamycin (GEM), tobramycin (TOB), cotrimoxazole (COT),norfloxacin(NOR), vancomycin(VAN), piperacillin-tazobactum(PTT), (- not tested)

The antibiotic susceptibility of E. coli, which was the most common causative pathogen of UTI in children during the period of this study, was highest to Imipenem (100\%),ciprofloxacin $(100 \%)$ followed by amikacin (97\%), nitrofurantoin(94.5\%), and coamoxiclav(87\%). E.coli showed low susceptibility to norfloxacin (61.1\%) and gentamycin (73.3\%).Klebsiella sensitivity pattern was almost similar to E.coli. Proteus was more resistant than E.coli to ciprofloxacin and amikacin. Other Enterobactericeae (acinetobacter, citrobacter) were universally sensitive to Imipenem, ciprofloxacin, amikacin and norfloxacin. Among CONS all were susceptible to vancomycin and was resistant to cotrimoxazole. Staph aureus was sensitive to vancomycin and ciprofloxacin.

\section{Discussion}

Urinary tract infections are common, potentially serious infection of childhood. Ccommunity acquired urinary tract infections (UTI) cause significant illness in the first 2 years of life and are considered as common disease in school and pre-school children ${ }^{(1-3)}$. Etiologic agents of UTI are variable and usually depend on time, geographical location and age of patients. However, Enterobactericeae species including Escherichia coli, Proteus mirabilis, Enterobacter agglomerans, Citrobacter freundii and Klebsiella pneumoniae account for over $70 \%$ cases $^{(2-5)}$. Based on the microbial sensitivity test results, drugs that are usually administered against uropathogens include cotrimoxazole, amoxicillin, ampicillin, amino glycosides, cephalosporin's, nalidixic acid and nitrofurantoin. However, many reports have indicated the presence of multi-drug resistance in organisms causing UTI ${ }^{(-9)}$. UTI cause acute morbidity as well as long term sequlae including hypertension and impaired renal function. A cause of occult febrile illness in up to $5 \%$ of young children they often remain undiagnosed. ${ }^{10}$

A total of 630 Children (1month to 5yrs) with fever were evaluated in the study of whom $69(10.9 \%)$ children [29 male (42\%) and 40 female $(57.9 \%)$ ] had culture proven UTI [68 bacterial and 1 due to yeast],of them 22( $31.8 \%)$ were 1 month to one year, 18(26.08\%) were 1-2 years,29(42\%) were 2-5 years age. There was an overall female preponderance in cases of UTI(57.9\%).Significant pyuria was seen in $128(20.3 \%)$ children, of whom $72(56.25 \%)$ were females, $56(43.75 \%)$ were males. $40(31.2 \%)$ of them were 1 month -1 yrs, $35(27.3 \%)$ were between 1-2 yrs and the rest 53(41.4\%) were 2-5 yrs of age,48(37\%) of children with pyuria showed 6-8 pus cells / HPF and 55(43\%) showed 8-10 pus cells / HPFand 20\% showed numerous pus cells. Most common organism isolated was E.coli 40(57.97\%) followed by Klebsiella 8(11.59\%), pseudomonas7 (10.14\%), proteus 4(5.79\%), CONS 4(5.79\%), staph aureus3 (4.34\%), Acinetobacterspp (1.4\%), citrobacter1 (1.4\%), Candida spp $(1.4 \%)$.

The antibiotic susceptibility of E. coli, which was the most common causative pathogen of UTI in children during the period of this study, was highest to Imipenem $(100 \%)$,ciprofloxacin $(100 \%)$ followed by amikacin (97\%), nitrofurantoin(94.5\%), and coamoxiclav(87\%). E.coli showed low susceptibility to norfloxacin $(61.1 \%)$ and gentamycin $(73.3 \%)$.Klebsiella sensitivity pattern was similar to E.coli. Proteus was more resistant than E.coli to ciprofloxacin and amikacin. Other Enterobactericeae (acinetobacter, citrobacter) were universally sensitive to Imipenem, ciprofloxacin, amikacin and norfloxacin. Among CONS all were susceptible to vancomycin and was resistant to cotrimoxazole. Staph aureus was sensitive to vancomycin and ciprofloxacin.

Prevalence of febrile UTI in infants in our study was higher $11.3 \%$ than the study by Dharni Dharaka et $\mathrm{al}^{12}(1993)$ who reported a prevalence of $5.4 \%$ in febrile infants and Hoberman et $\mathrm{al}^{11}(1993)$ who reported prevalence of $5.3 \%$ in infants. Overall prevalence of UTI in febrile children in our study was $10.9 \%$ and $11.3 \%$ in children $<5$ years and infants respectively in contrast to study conducted by R.K.Kaushal ET al ${ }^{13}$ (2003) who reported higher prevalence of $8.4 \%$ and $12.3 \%$ in children $<5$ years and infants respectively. Prevalence of febrile UTI in infants in our study(11.3\%) was higher compared to report by Shaw K.N et al ${ }^{14}(1998)$ from USA who reported prevalence of $3.3 \%$ in febrile infants. In our study prevalence of UTI in $<2$ years age group was $10.25 \%$ which was higher than the study by Roberts k.et $\mathrm{al}^{15}(1983)$ who quoted prevalence of $4.1 \%$.P.R Srivasths et $\mathrm{al}^{16}(1996)$ reported a prevalence of $2.48 \%$ in children $<2$ years which was lowest reported from a developing country.

Bryan C.S et $\mathrm{al}^{17}$ reported E.coli as the common urinary pathogen in $85 \%$ of cases. According to Aravind Bagga et $\mathrm{al}^{18}$ (2000) $90 \%$ of first symptomatic urinary tract infection and $70 \%$ reoccurrence infection were due to E.coli. Hoberman et $\mathrm{al}^{11}$ (1993) reported as E.coli as the most common bacterium isolated in his study. All these studies correlate with our study with E.coli being commonest isolate.

In our study $70 \%$ of children who showed numerous pus cells were culture positive and $54 \%$ were culture positive who showed 8 to 10 pus cells and $43 \%$ of children showing 6-8 pus cells were culture positive. Hence the presence of pyuria of $>51$ eukocytes/HPF in a centrifuged sample is a significant indicator of UTI.

The study would have been more conclusive if urine culture were done in all febrile children screened, but economical constraints limited us to do urine culture only in those children showing significant pyuria of $>5$ pus cells/HPF of centrifuged urine sample and we found that $53 \%$ of febrile pyuric children were culture positive. 


\section{Conclusions}

Our tertiary centre caters to a group of children at high risk of UTI as can be estimated from the 10.9 per cent culture positivity. Similar situations exist in other parts of India, albeit the load has not been studied in children ${ }^{20,21}$. Important facts emanating from the present study include (i) infants $(31.8 \%)$ represent a significant group vulnerable to UTI (ii) Male gender is clearly a risk factor towards acquiring UTI in infancy similar to taneja et al ${ }^{21}$ after which females predominant. E coli $(47.1 \%)$ was the leading etiology of pediatric UTI at our center, multidrug resistant microbes (K. pneumonia, $\mathrm{p}$. aeruginosa) were responsible for a substantial proportion of infections, however, staphylococci were not found to play a major role in UTI at our center $(<2 \%)$ unlike reports from else were ${ }^{21,22}$. Co-trimoxazole and Norfloxacin once the mainstay in treatment of UTIs, were no longer useful at our center. Our study would have been more conclusive if urine culture was done in all febrile children and those children with known genitourinary anomalies.

\section{References}

[1]. Schlager T. Urinary tract infections in infants and children. Infect Dis Clin North Am. 2003; 17: $353-365$.

[2]. Wald ER. Cystitis and pyelonephritis. In: Feigin RD, Chery JD, Demmier GJ, Kapian SL, eds. Textbook of Pediatric Infectious Diseases, 5th edn, Philadelphia: Saunders 2004; p 541-53.

[3]. Fallahzadeh MH, Alamdarlu HM. Prevalence of urinary tract infection in pre-school febrile children. Iranian J of Med Sci 1999; 24 : 35-39.

[4]. Ma JF, Shortliffe LM. Urinary tract infection in children: etiology and epidemiology. UrolClin North Am 2004; 3: 517-526.

[5]. Adjei O, Opoku C Urinary tract infections in African infants. Int J Antimicrob Agents 2004; 24 Suppl 1: S32 -34.

[6]. Yüksel S, Oztürk B, Kavaz A, Ozçakar ZB, Acar B, Güriz H, et al. Antibiotic resistance of urinary tract pathogens and evaluation of empirical treatment in Turkish children with urinary tract infections. Int J Antimicrob Agents 2006; 28: 413-416.

[7]. Yildiz B, Kural N, Durmaz G, Yarar C, Ak I, Akcar N. Antibiotic resistance in children with complicated urinary tract infection. Saudi Med J 2007; 28: 1850-1854.

[8]. Mathai D, Jones RN, Pfaller MA. SENTRY Participant Group North America. Epidemiology and frequency of resistance among pathogens causing urinary tract infections in 1,510 hospitalized patients: a report from the SENTRY Antimicrobial Surveillance Program (North America). DiagnMicrobiol Infect Dis 2001; 40: 129-136.

[9]. Kahlmeter G. Prevalence and antimicrobial susceptibility of pathogens in uncomplicated cystitis. The ECO SENS study. Int J Antimicrob Agents 2003; 22: 49-52.

[10]. Zorc JJ, Kiddoo DA, Shaw KN. Diagnosis and management of Pediatric urinary tract infections. clin microbiol rev 2005; 18 : 417 422

[11]. Hoberman A, Chao HP, Keller DM, Hickey R, Davis HW, Ellis D. Prevalence of uninary tract infection in febrile infants. J pediatr $1993 ; 123: 17-23$.

[12]. Dharnidharka VR. Prevalence of bacteriuria in febrile infants. Indian Pediatr 1993; 30: 981-986

[13]. Kaushal R.K, Bansal S, Sharma V.K, Sood A, Goyal A Urinary tract infection among children presenting with fever. Indian Pediatr 2003; 40:269-270.

[14]. Shaw KN, Gorelick MH. Urinary tract infection in the pediatric patient.Pediatric clinics of North America 1999; $46: 6$.

[15]. Roberts KB, Charney E, Sweren RJ, Ahonkhai VI, Bergman DA, coulter MP et al: Urinary tract infection in infants with unexplained fever: a collaberative study. $J$ Pediatr 1983; 103: 864-867.

[16]. Srivaths PR, Rath B, Krishanprakash S, Talukdar B et al: Usefulness of screening febrile infants for urinary tract infection. Indian Pediatr 1990; 33: 218-220

[17]. Bryan CS, Reynolds KL. Community acquired Bacteremic urinal; tract infection: Epidemiology and Outcome. $J$ Urol 1984; 132 : $490,934$.

[18]. Bagga A, Sharma J. Urinary tract infections clinical features, evaluation and treatment. Pediatr today 2000; 3: 395-401

[19]. Clinical and Laboratory Standards Institute. Performance standards for antimicrobial susceptibility testing; $17^{\text {th }}$ informational supplement, CLSI M100-S17. Vol. 27 no.1. Wayne, PA: Clinical and Laboratory Standards Institute: 2007.

[20]. Navaneeth BV, Belwadu S, Suganthi N. Urinary pathogens' resistance to common antibiotics: a retrospective analysis. Trop Doct $2002 ; 32: 20-2$.

[21]. Taneja N, Chatterjee SS, Singh M, Singh S, Sharma M. Pediatric urinary tract infections in a tertiary care center from north India Indian J Med Res. 2010 Jan; 131:101-105.

[22]. Mohammed A, Mohammed S, Khan AU. Etiology and antibiotic resistance patterns of community acquired urinary tract infection in JNMC Hospital Aligah, India. Ann Clin Microbiol Antimicrob 2007; $6: 4-11$. 